\title{
Impacts of Covid-19 on Consumption-Related Industries Based on Fama-French Five Factor Model
}

\author{
Yizi Jiang ${ }^{1, \dagger}{ }^{\dagger}$ Yuanyu $\mathrm{Li}^{2,{ }^{\dagger}}$ Jiaqi Ruan ${ }^{3, *},{ }^{\dagger}$
}

\author{
${ }^{1}$ School of Government, Central University of Finance and Economics \\ ${ }^{2}$ Institute of Finance, Capital University of Economics and Business \\ ${ }^{3}$ International Business School, Shanghai University of International Business and Economics \\ These authors contributed equally. \\ *Corresponding author. Email: 18001161@suibe.edu.cn
}

\begin{abstract}
Covid-19 has brought a significant impact on people's daily life by influencing various industries. To discuss the impact of Covid-19 on consumption-related industries, this paper chose four industries of Agriculture, Food, Soda and Beer industries of the U.S. market. Based on Fama-French Five Factor Model, multi-regression analysis was adopted on daily returns before and after the breakout of Covid-19. The coefficients of the five factors before and after Covid19 were obtained and compared. The results indicate that market risks are still significant in these four industries, and the Food industry may have higher market risks so that people are expecting a higher return. Besides, no matter how large the scale of the companies, the consumption-related industries were influenced by Covid-19 to a large extent. In addition, since the Food industry needs to stay stable in terms of profits level risks, the lower the Food industry has, the more the excess return to the individual stock will be. However, even these four industries were both influenced by Covid-19, people were still confident with the Food industry. They considered it was the first option to invest compared to the Beer and Soda industries. Therefore, the volatility and vulnerability of a specific sector can be analysed. Then it is possible to choose the stable sectors to build portfolios, which is possible to obtain a more stable return in this special period.
\end{abstract}

Keywords: Fama-French Five Factor Model, Covid-19, Stock Market.

\section{INTRODUCTION}

\subsection{Background}

As the Covid-19 pandemic progresses, the issue of food security has become the focus of the public. Although the major food shortage is not serious yet, the impact of Covid-19 on food supply, demand, price, and trade between countries has already influenced people's daily life.

Many countries around the world experienced a short period of city disclosure because of Covid-19. Before the government took action, residents hoarded flour, vegetables, dairy products, and seasoning like salt. The consumers' increasing demand caused the price of food to rise sharply. According to the Food and Agriculture Organization of the United Nations (FAO), the food price index began a new round rise from May
31, 2020, and this upward trend continued until May 31, 2021.

At the same time, lots of problems arose on the supply side. For instance, the food processing factories closed due to the rupture of the capital chain, which affected the retail industry. Many companies lay off reduced the staff's income, which made some of them unable to afford the food or turn to purchase some less nutritious food. Supply-side problems have also led to a rise in food prices in a specific period.

In addition, in less than two months after the outbreak of Covid-19, 22 countries have launched export restrictions on one or more kinds of food. Although most of these export restrictions were lifted at the end of June, the limitations caused serious food shortages in countries that rely heavily on imported food. On the other hand, this also reduced profits for countries exporting food. 


\subsection{Related Research}

Given the enormity of the current epidemic, more and more researchers have begun to examine the impact of Covid-19 on the stock market. Baker et al. considered that Covid-19 had influenced the stock market to a great extent. They used text-based methods to develop their points, and they also put forward the potential explanations for the unprecedented stock market reaction to the pandemic. They suggested that the government restrictions on commercial activity are the main reasons the U.S. stock market reacted so fiercely to Covid-19 than to previous pandemics. Therefore, the government need to solute the health crisis created by Covid-19 and change to fewer containment policies for the economy [1]. Hee Soo Lee investigated the initial impact of Covid-19 sentiment on the US stock market using big data. The study searched the relationship between Covid-19 sentiment and 11 sector indices of the United States stock market. Besides, Hee Soo Lee examines whether Daily News Sentiment Index changes predict US industry returns differently by estimating the time series regression model. The result suggests the strategic investment planning considering the time lag perspectives by visualizing changes in the correlation level by time lag differences [2]. Enrico investigated the impact of Covid-19 cases and related deaths on the US stock market by using the GARCH model to analyse data on VIX, the S\&P500 and the Dow Jones index from 8 April 2019 to April 2020. The result shows that changes in the number of cases in the US in the first 3 months of 2020 did not impact the stock market. Still, there is evidence of a positive impact on the conditional heteroscedasticity of the Dow Jones and S\&P returns. Volatility is critical to the operation of the financial market, it acts as a barometer of financial risk, and different industries react differently when facing Covid19 [3].

Fama-French model was also a common tool to be used when different researches were done. Yi Sun examined the performance of the Fama-French FiveFactor model in the US market before and after the Covid-19 outbreak. OLS method was applied to 49 Fama-French industry portfolios, and Yi Sun found that the efficiency of the Fama-French Five-Factor model strengthened after the outbreak in all industries, but unexplained factor behavior also increased. The results showed Fama-French factors beta of most industries changed significantly [4].

At the same time, there is also much other research about the influence Covid-19 has brought to the financial market. Zeren and Hizarc1 investigated the impact on the stock market of the Covid-19 Coronavirus epidemic. They used the daily data of total death and total cases from 23 January 2020 to 13 March 2020 and researched the Maki cointegration test. Zeren and Hizarc1 suggested that investors should turn their investments into gold rather than stock markets. Also, turning to cryptocurrencies has been seen as another alternative option for investors. In this way, it is a preferred option that the investors should invest in the derivatives markets and the stock markets of countries where Covid-19 is relatively rare to avoid financial risk [5]. Gormsen and Koijen researched how investors' expectations about economic growth changed during the coronavirus outbreak and subsequent policy. They used data from the aggregate stock market and dividend futures until 2020 and concluded a simple crisis model to understand the joint dynamics of short-term dividend futures. In this way, they found that dividend futures can be useful when the market participants update market information and forecast the market trend [6].

Especially, food-related industries' performance was researched from different aspects after the outbreak of Covid-19. Julia and Alfons investigated the impact on stock price volatility and profits of companies in the food supply chain of the Covid-19 Coronavirus epidemic. They used a data set of 71 major listed companies in the food value chain from stock indices in the US, Japan and Europe. They calculated the annualized volatility per sector, screened the contents of the reports for stated effects of the pandemic on profits, and analyzed stock price reactions in four different phases of the pandemic. The results showed high volatility in the stock price in manufacturers of fertilizers, agrochemicals, and food distributors. However, food retails had low volatility in stock price. By doing regression analysis, Julia and Alfons found that stocks of more profitable companies gained higher cumulative returns during the outbreak but received higher discounts on returns after this period [7]. Mazur et al. investigated the US stock market performance during the crash of March 2020 triggered by Covid- 19 . They use the universe of the Standard and Poor's 15 firms for the month of March 2020 and found the food industry performed well in this period because restaurants and catteries had been shut down. Other well-performed industries include natural gas, health care and software. While firms operating in crude petroleum, real estate, entertainment, and hospitality sectors plummet considerably, losing more than $70 \%$ of their market capitalizations, and these stocks showed extreme volatility [8]. Baek et al. investigated the relationship between the Covid-19 pandemic and financial market volatility. They analysed daily U.S. stock index values, macroeconomic indicators, and the daily number of Covid-19 cases from 2nd January 2020 to 30th April 2020 by using the Markov Switching regime $\mathrm{AR}$ model and the machine learning feature selection method. The results show a significant increase in total risk for the US stock market and industries most impacted by negative aggregate demand shocks, such as restaurants exhibited the largest increases in risk. In contrast, industries such as food 
production with steady or increased demand exhibited smaller changes [9]. Stephens et al. investigated the impacts on agricultural and food systems brought by Covid-19. They researched the whole impacts from five different aspects: food security, labour availability, farm system resilience, agriculture system connectivity, and other questions. From their perspective, they thought Covid-19 brought serious food security problems so that people with low income were hurt. Also, if Covid-19 is not contained, the free and safe movement of agri-food workers will not be attainable for the foreseeable future. As for agricultural connectivity, since the closure of the ports vastly reduced freight capacity for agricultural goods, access to agricultural markets was limited. Thus, this may negatively impact agricultural productivity [10].

\subsection{Objective}

The food industry is an indispensable part of people's daily life. At the same time, it belongs to the whole consumption-related industries. Considering the universality and applicability of the research, we need to broaden our scope. Thus, four consumption-related industries, which were Agriculture, Food, Soda and Beer industries, were chosen as the main research objectives.

To explore the impact of Covid-19 on the Agriculture, Food, Soda and Beer industries, the FamaFrench Five Factor Model was adopted to analyse the stocks of these four industries. In addition, the research studied how the market reacted to this global pandemic, especially those industries that were closely related to people's daily life.

\section{METHOD}

After Markowitz proposed the Mean-Variance Model, Sharpe et al. proposed the CAPM Model based on a series of preconditions. However, these preconditions make CAPM Model ineffective when it applies to the stock market. To capture the relations between the average return and size and the relations between average return and price ratios, like B/M, Fama and French proposed Fama-French Three-Factor Model [11]. By adding SMB (portfolio size) and HML (bookto-market value ratio), the Fama-French Three-Factor Model can better explain different return patterns.

The model is expressed as follows:

$$
\begin{aligned}
R_{i t}-R_{F t}=a_{i}+ & b_{i}\left(R_{M t}-R_{F t}\right)+s_{i} S_{M B}+h_{i} H_{M L} \\
& +e_{i t}
\end{aligned}
$$

where $R_{i t}$ is the return on security or portfolio $i$ for period $t, \mathrm{R}_{\mathrm{Ft}}$ is the risk-free return, $\mathrm{R}_{\mathrm{Mt}}$ is the return on the value-weight market portfolio, $\mathrm{SMB}_{\mathrm{t}}$ is the return on a diversified portfolio of small stocks minus the return on a diversified portfolio of big stocks, $\mathrm{HML}_{t}$ is the difference between the return on diversified portfolios of high and low $\mathrm{B} / \mathrm{M}$ stocks and $\mathrm{e}_{\mathrm{it}}$ is a zero-mean residual. If the three factors, $b_{i}, s_{i}$, and $h_{i}$ capture all variation in expected return, the intercept $\mathrm{a}_{\mathrm{i}}$ is zero for all securities and portfolios i. In other words, FamaFrench Three-factor Model can be used to analyze the risk or return of any fund. But subsequent evidence shows that Equation (1) is an incomplete model because its three factors neglect the variation in average return that related to profitability and investment.

As a result, Fama and French added another 2 factors into their model in 2015 and formed the FiveFactor Model:

$$
\begin{aligned}
\mathrm{R}_{\mathrm{it}}-\mathrm{R}_{\mathrm{Ft}}=\mathrm{a}_{\mathrm{i}}+ & \mathrm{b}_{\mathrm{i}}\left(\mathrm{R}_{\mathrm{Mt}}-\mathrm{R}_{\mathrm{Ft}}\right)+\mathrm{s}_{\mathrm{i}} \mathrm{SMB}_{\mathrm{t}}+\mathrm{h}_{\mathrm{i}} \mathrm{HML}_{\mathrm{t}} \\
& +\mathrm{r}_{\mathrm{i}} \mathrm{RMW}_{\mathrm{t}}+\mathrm{c}_{\mathrm{i}} \mathrm{CMA}_{\mathrm{t}}+\mathrm{e}_{\mathrm{it}}
\end{aligned}
$$

where $\mathrm{RMW}_{\mathrm{t}}$ reflects the profitability of different portfolios of stocks and $\mathrm{CMA}_{\mathrm{t}}$ represents a couple of different investment styles, which Fama and French called them 'conservative and aggressive'. Just like the Three-Factor model, if the five factors capture all variation in expected return, the intercept $a_{i}$ in Equation (2) is zero for all securities and portfolios $i$.

\section{RESULTS}

This study adopted the Fama-French Five Factor Model to research how the stock market was influenced before and after Covid-19. Since Covid-19 broke out on 20 January 2020 in China and spread out of the world quickly in the following 2-3 months, this research chose 1 March 2020 as the division point in this study. Then, the period between 1 June 2019 and 1 March 2020 was chosen as the Fore-Covid-19 period, and the period between 1 March 2020 and 30 November 2020 was chosen as the After-Covid-19 period. About the industries, this study selected to investigate, four consumption-related industries, including Agriculture, Food, Soda and Beer, were chosen as the research industries because the consumption-related industries played an indispensable role in our life, and they may perform more violent fluctuation in the stock market when Covid-19 broke out.

According to Fama-French Five Factor Model used in the research, data of five factors of $M k t-R_{f}, S M B$, HML, RMW and CMA from the CRSP database were obtained. After calculating $\mathrm{R}_{\mathrm{i}}-\mathrm{R}_{\mathrm{f}}$ and intergrading all the data of five factors, multi-regression analysis was applied to get the results below. 
Table 1. Descriptive Regression Statistics In Four Consumption-Related Industries 'Fore' and 'Aft' The Outbreak

\begin{tabular}{|c|c|c|c|c|c|c|c|}
\hline Industry & Item & Period & Mkt-Rf & SMB & HML & RMW & CMA \\
\hline \multirow{4}{*}{ Agriculture } & \multirow{2}{*}{ Coefficients } & Fore & 1.0406 & 0.7116 & -0.1314 & 0.3723 & 0.0281 \\
\hline & & Aft & 0.8752 & 0.0585 & 0.4988 & -0.0450 & -0.3529 \\
\hline & \multirow{2}{*}{ P-value } & Fore & 0.0000 & 0.0036 & 0.5937 & 0.3604 & 0.9523 \\
\hline & & Aft & 0.0000 & 0.7300 & 0.0004 & 0.8773 & 0.3363 \\
\hline \multirow{4}{*}{ Food } & \multirow{2}{*}{ Coefficients } & Fore & 0.6159 & -0.1869 & -0.0745 & -0.4059 & 0.9108 \\
\hline & & Aft & 0.7469 & -0.0213 & -0.0850 & -0.4028 & 1.0118 \\
\hline & \multirow{2}{*}{ P-value } & Fore & 0.0000 & 0.0497 & 0.4411 & 0.0117 & 0.0000 \\
\hline & & Aft & 0.0000 & 0.7605 & 0.1370 & 0.0010 & 0.0000 \\
\hline \multirow{4}{*}{ Soda } & \multirow{2}{*}{ Coefficients } & Fore & 0.6793 & -0.6409 & -0.0635 & -0.2664 & 0.7933 \\
\hline & & Aft & 0.7889 & -0.1040 & 0.1279 & 0.1602 & 0.7013 \\
\hline & \multirow{2}{*}{ P-value } & Fore & 0.0000 & 0.0000 & 0.6178 & 0.2054 & 0.0013 \\
\hline & & Aft & 0.0000 & 0.3028 & 0.1204 & 0.3562 & 0.0015 \\
\hline \multirow{4}{*}{ Beer } & \multirow{2}{*}{ Coefficients } & Fore & 0.7079 & -0.3939 & -0.2263 & -0.1198 & 0.7248 \\
\hline & & Aft & 0.9284 & -0.1081 & -0.1240 & -0.1334 & 1.0104 \\
\hline & \multirow{2}{*}{ P-value } & Fore & 0.0000 & 0.0001 & 0.0289 & 0.4806 & 0.0003 \\
\hline & & Aft & 0.0000 & 0.2715 & 0.1224 & 0.4300 & 0.0000 \\
\hline
\end{tabular}

As shown in Table 1, it compared each industries' performance before and after Covid-19. The factor SMB became not significant, and the factor HML was in contrast in the Agriculture industry. As for the Food industry, only the SMB factor became insignificant after Covid-19 while the other four factors remained the same significant degree as before Covid-19. Similarly, only the SMB factor changed its significant degree in the Soda industry, just like the Food industry. In terms of the Beer industry, two factors' significant degree changed before and after Covid-19. Its two factors, which were SMB and HML, both became not significant. All in all, the results demonstrated that Agriculture and Beer industry fluctuated more violently during Covid-19.

\section{DISCUSSION}

\section{1. $M k t$}

Mkt-Rf is the excess return of the market relative to the risk-free investment. This factor demonstrates the market risks that cannot be diversified. So, the higher the Mkt-Rf factor, the higher the market risk will be, and the higher return the investors might require.

As is shown in Table 1, the impact of Covid-19 on the four consumption-related industries is not obvious because the P-value is really close to zero before and after Covid-19, which means that the Mkt factor is significant to Agriculture, Food, Soda and Beer industries. However, the coefficient decreased in
Agriculture and Soda industries but increased in Food and Beer industries. This means people may require a higher return in the Food and Beer industries. That may be because the impact on the Food industry brought by Covid-19 was so significant that people had to cook and eat at home, and the demand for food was reduced. In this way, the Food industry may have higher market risks to expect a higher return.

\section{2. $S M B$}

SMB represents the simulated portfolio return of the size factor at $\mathrm{t}$ period, which means excess return depends on the company size.

As shown in Table 1, Food, Soda and Beer industries all have negative $\beta$ _SMB, demonstrating that large-scale stocks are preferred and large-scale stocks have a greater impact on excess return. While agriculture industry has positive $\beta$ SMB, which means small-cap companies are more welcomed. Overall, in consumption-related industries, stock markets are more inclined to large enterprises. This can be interpreted in different ways. Large-scale enterprises have economics of scale. Therefore, they can have a cost advantage and shared resources, like a comparatively stable supply chain and shared customer database. Besides, largescale enterprises have more abundant cash flow and a stronger ability to defend risks because they have more mature management and strategy. As for consumptionrelated industries, the cost advantage and consumer 
market insight are extremely important, explaining why large-scale enterprises are preferred in the stock market.

On the other hand, by comparing the data before and after Covid-19, all four industries' SMB significant level change from significant to not significant, which implies that the SMB factor becomes ineffective in the Fama-French Model after the outbreak of Covid-19. As Covid-19 boomed, consumption-related industries, as the most basic industries in our daily lives, were influenced greatly because the whole industries demand dropped sharply. People must stay at home and had fewer parties and fun than before to control the spread of Covid-19. Thus, fewer consumption-related products, like beer, soda, and dairy products, were in need. That is to say, no matter how large the enterprises' scale was, the industries were less likely to offset the negative impact brought by Covid-19.

\section{3. $H M L$}

HML equals the high $\mathrm{B} / \mathrm{M}$ ratios minus the low $\mathrm{B} / \mathrm{M}$ ratios, which demonstrates the relative movement of the stock in response to the Book-to-Market ratio premium, and HML is the simulated portfolio return of the $\mathrm{B} / \mathrm{M}$ factor at time $\mathrm{t}$.

According to the data in Table 1, all the industries have negative HML coefficients before Covid-19. The Low $\mathrm{B} / \mathrm{M}$ ratio reveals the market has overestimated these Food industries, and this may be because food is essential in our daily lives. Thus, people may pay more attention and have higher expectations toward it.

After the impact of Covid-19, the HML factors of the Agriculture and Soda industries became positive, while the Food and Beer industries still had negative HML coefficients. This trend showed a lower market valuation, and people began to lose optimism for these industries. Thus, Agriculture and Soda industries were underestimated. This can be interpreted in different ways. Maybe large numbers of companies cannot handle the influence of Covid-19, and people turned to firms with higher B/M Ratios because they think they have a stronger ability to offset the negative impacts.

However, the HML factor of the Food industry was still negative, which reveals people were still confident with the Food industry. Compared to the Beer or Soda industries, Food is a necessity in daily life, especially in the period of Covid-19. Although the demand for food decreased, people still considered it was the first option to invest.

\section{4. $R M W$}

RMW stands for profits level risk, which often represents that industries with higher risks generally may produce higher profitability.
As the data demonstrates above, E(RMW) influences the excess return of the individual stocks in four consumption-related industries to different degrees. This factor's significant level all remained the same before and after Covid-19 in four industries. What needs to be paid attention to is that only the Food industry has an RMW factor of significant level. In contrast, the other three industries, including Agriculture, Soda and Beer, all have insignificant RMW factors.

More specifically, these four industries all underwent comparatively small impacts brought by Covid-19. This phenomenon has different interpretations. Consumption-related industries provide the basic products for daily life, including food, water, and daily consumables. Although Covid-19 shocked the whole market, the basic consumption products demand was still stable. In terms of the Food industry, unlike the 2007-2008 global food crisis, the risk of food shortage is not a long-term problem, and global food reserves remain ample. Otherwise, all the countries took action to stabilize the Global Food Supply Chain, which means Covid-19 influenced the whole industry within control.

In addition, the coefficients of the Food industry remain negative before and after Covid-19, which means when the industry has lower risk, it has higher profitability. It is easy to comprehend. The food industry needs to be stable. Therefore it tends to have lower risks. When the Food industry fluctuates violently or has higher risks, negative impacts will happen. For example, several social security problems will burst out. When the price rises, people with low or middle income will face rising price pressure. Thus, this may influence people's life quality. Furthermore, food price is also a very important factor in influencing world economic trends. Hence, the lower the food industry's risks, the more the excess return to the individual stock will be.

\section{5. $C M A$}

CMA demonstrates the risk of the investment. If the investors are risk-averse, they will always require a higher yield when the risk is higher, which is, in this part, a higher CMA. As shown in Table 1, it is easier to understand the impact of Covid-19 on some industries by analysing the coefficients and the P-value.

The significance level remained unchanged after the breakout of Covid-19. That is to say, the risk of investment didn't change much because of Covid-19. However, according to Table 1 , the coefficients of the Agriculture industry turned from positive to negative, while other industries remained positive. In addition, the coefficients of Agriculture and Soda decreased while the coefficients of Food and Beer increased.

The CMA factor remained insignificant in explaining the excess return of the stock in the Agriculture and Soda industries. In contrast, the CMA 
factor is just significant for Food and Beer industries. So, these four industries can be divided into two parts. One is Agriculture and Soda. In this part, there is no strong link between the excess return in these two industries with the CMA factor and the coefficients both decreased. Another is Food and Beer industries. In this part, there is an obvious link between the excess return and the CMA factor, and the coefficients increased.

The CMA decreased after the breakout of the pandemic, which means people demand lower excess returns for the Agriculture and Soda industries. That is probably because people have enough confidence in the Agriculture industry. Since in the United States, the big farm is the main form of agriculture. Unlike East and South Asia, farmers must get together to plant and harvest. Because of Covid-19, they could not work together, so the Agriculture industry might be influenced. However, in the United States, farm holders could use planes or other instruments to work. Therefore, they were less influenced by Covid-19.

On the other side, the Food industry was heavily influenced. The CMA factor increased $21 \%$, which means that people thought it was risky to invest in the Food industry. That is easy to explain because, during Covid-19, many people chose to eat more frequently at home rather than outside or just took away the food from the restaurant. Many restaurants closed after the breakout of Covid-19.

\section{CONCLUSION}

The agriculture and Beer industries fluctuated during Covid-19 more severely from the stock market aspect. Relatively, Food and Soda industries performed more stable during the Covid-19 period.

Investor's risk and the stock expected return have always been hot topics in academic circles. This paper adopted Fama-French Five Factor model to evaluate the impact of Covid-19 on corporates' returns in the Agriculture, Soda, Beer and Food sectors. From the analysis above, Mkt-Rf became a more important factor after Covid-19, and the SMB indicates investors more prefer large-scale stocks due to their stronger ability to defend risks. Also, Food and Beer industries' negative HML reveals people still trust them, while people became pessimistic about Soda and Agriculture industries comparatively. Besides, although the RMW demonstrates Covid-19 slightly struck those four industries, some changes still can't be ignored. Because the overall volatility increased in the US financial market, the CMA shows people require a higher return on Food and Beer industries. Investors should be more careful when investing towards smaller-cap and fewer investment activities businesses, especially those Soda or Agriculture-related businesses. The Food industry might become a hot investment field during the postpandemic period.

\section{REFERENCES}

[1] Baker, S. R., Bloom, N., Davis, S. J., Kost, K. J., Sammon, M. C., \& Viratyosin, T. (2020). The Unprecedented Stock Market Impact of COVID-19. National Bureau of Economic Research.

[2] Lee, H. S. (2020). Exploring the Initial Impact of COVID-19 Sentiment on US Stock Market Using Big Data. Sustainability, 12(16), 6648-6648.

[3] Onali, E. (2020). COVID-19 and Stock Market Volatility. Social Science Research Network.

[4] Sun, Y. (2021). Analysis of Fore and Aft Covid-19 Impact on Industry Data Based on Fama-French Five Factors. In 2021 International Conference on Electronic Commerce, Engineering Management and Information Systems.

[5] Zeren, F, Hizarc1, A . (2020). THE IMPACT OF COVID-19 CORONAVIRUS ON STOCK MARKETS: EVIDENCE FROM SELECTED COUNTRIES . Muhasebe ve Finans İncelemeleri Dergisi , 3 (1) , 78-84 .

[6] Gormsen, N. J., \& Koijen, R. S. J. (2020). Coronavirus: Impact on Stock Prices and Growth Expectations. The Review of Asset Pricing Studies, 10(4), 574-597.

[7] Höhler, J., \& Lansink, A. O. (2021). Measuring the impact of COVID-19 on stock prices and profits in the food supply chain. Agribusiness, 37(1), 171186.

[8] Mazur, M., Dang, M., \& Vega, M. (2021). COVID-19 and the march 2020 stock market crash. Evidence from S\&P1500. Finance Research Letters, 38, 101690.

[9] Baek, S., Mohanty, S. K., \& Glambosky, M. (2020). COVID-19 and stock market volatility: An industry level analysis. Finance Research Letters, 37,101748 .

[10] Stephens, E. C., Martin, G., Wijk, M. van, Timsina, J., \& Snow, V. (2020). Editorial: Impacts of COVID-19 on agricultural and food systems worldwide and on progress to the sustainable development goals. Agricultural Systems, 183, 102873 .

[11] Fama, E. F., \& French, K. R. (2017). International tests of a five-factor asset pricing model is . Journal of Financial Economics, 123(3), 441-463. 